\title{
Child-Pugh Class A6
}

National Cancer Institute

\section{Source}

National Cancer Institute. Child-Pugh Class A6. NCI Thesaurus. Code C146791.

A total score of 6 for hepatic function, corresponding to class A in the Child-Pugh classification. 